\title{
Post-Acquisition Integration Strategies- Some illustrative evidence from Chinese acquisitions of Italian luxury firms
}

\author{
Alessandra Vecchi \\ University of Bologna \\ E-mail: alessandra.vecchi@unibo.it
}

\begin{abstract}
Outward Foreign Direct Investment (OFDI) from emerging economies has begun to increase significantly and has been growing at a faster pace than FDI from the developed world. This research seeks to assess the impact of Chinese acquisitions and their implications for the Italian firms in the luxury sector. By relying on two in-depth case-studies, this paper presents a cross-case analysis of four Chinese acquisitions in order to provide some indepth insights into the post-acquisition integration strategies implemented by the Chinese investors in the luxury Made in Italy sector. The study contributes to our understanding of how emerging market firms implement postacquisition integration strategies when acquiring firms from advanced economies. To this end, the benefits and challenges associated with the post-acquisition integrations strategies implemented by the Chinese investors were identified.
\end{abstract}

Keywords: OFDI, Chinese acquisitions, Post-acquisition strategy, Integration strategy, Made in Italy, luxury manufacturing sector

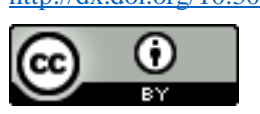

2523-6547 - Copyright: (C) 2017 The Authors. This is an open access article distributed under the terms of the Creative Commons Attribution License, which permits unrestricted use, distribution, and reproduction in any medium, provided the original author and source are credited. 


\section{Introduction}

While traditionally Foreign Direct Investment (FDI) flowed from advanced developed economies into developed and developing countries, more recently, a new trend has emerged in the pattern of FDI. Outward FDI (OFDI) from emerging economies has begun to increase significantly and has been growing at a faster pace than FDI from the advanced developed world. Increasingly, Multinational Corporations (MNCs) from emerging economies are buying business assets and capabilities in the luxury sector all over Europe. These MNCs from emerging economies (EMNCs or EMNEs) have been the subject of recent interest, seen in a growing number of studies (Guillen and Garcia-Canal, 2012; Kale and Singh, 2012; Williamson et al, 2013). According to Marchand (2015), two elements can explain this interest. First, the scope and pace of the international expansion by emerging economy firms has been exceptional. Second, the patterns of international expansion by emerging economy firms have raised questions about their originality and whether existing theories of international expansion strategies are adequate or need to be modified (Vecchi 2013a, 2013b, 2014a, 2014b, 2016; Vecchi and Brennan, 2014).

There is a stream of work that deals with the internationalization of Emerging Market Multinational Corporations (EMNCs). Despite being both embedded and exposed to a wide variety of national settings, the literature identifies some common features in their recent internationalization patterns (Demirbag at al., 2009, 2010a, 2010b; Demirbag and Yaprak, 2015). In relation to EMNCs being embedded in their home market Cuervo Cazurra and Ramamurti (2015) argue that some "push" factors that may have also driven them to invest in advanced countries. They label the resulting OFDI as 'escape investments', which are motivated by the desire to escape the home country's weak institutions and economic underdevelopment. Additionally, the "pull" factors, such as the large markets and wealthier consumers of advanced countries, play an important role. In particular, some common challenges faced by EMNCs include a liability of emergingness (Madhok and Keyhani, 2012), existing knowledge, technological and commercial gaps between themselves and their developed countries counterparts (DMNCs) (Deng, 2010; Demirbag and Yaprak, 2015), the poor image associated with their corporate social responsibility (Liou et al., 2012) often coupled by controversial political relations in the host markets (Gammelthoft and Pradhan, 2010). Nonetheless, there are also significant benefits that they bring into the new global production system. These are namely the introduction of disruptive business models as well as a fresh perspective (Chattopadhyay et al., 2012). Within this work, there is the acknowledgement that the challenges EMNCs face motivate them to undertake an accelerated internationalization strategy (Fortanier and Van Tulder, 2008), especially by extensively relying on Mergers and Acquisitions (M\&As). M\&As are often used as a strategic vehicle that enable EMNCs to acquire both tangible and intangible strategic assets to ultimately overcome their competitive disadvantages in being latecomers to the international business activity and lacking the resources and capabilities to be successful in the international arena (Luo and Tung, 2007; Rui and Yip, 2008; Deng, 2010). M\&As are thus perceived as shortcuts (Vecchi, 2016) to catch up with DMNCs (Madhok and Keyhani, 2012), to also secure well-established Western brands, and to gain immediate access to advanced technology (Vecchi 2013a, 2013b, 2014a, 2014b, 2016; Vecchi and Brennan, 2014; Brennan, 2015). Differently from other modes of entry, M\&As give EMNCs more direct control over the operation of, and its associated returns (Child and Rodriguez, 2005), by therefore offering significant value-creation opportunities that may not otherwise be available to them (Rabbiosi et al 2012). However, while EMNCs are gaining considerable attention, we still know very little about their post-entry activities such as their implementation of post-acquisition and integration strategies. In particular, with relatively less international experience, we might expect that EMNCs will face radically different challenges when compared to their Western counterparts. These include negative country of origin perceptions, consumer bias and heightened levels of consumer ethnocentrism which may undermine the success on their products, brands, and marketing strategies.

The international expansion of emerging economy firms is particularly relevant to Italy and its manufacturing luxury sector. Italy has a traditional competitive advantage in the production of luxury products (Vecchi, 2008, 2013, 2016). The Italian luxury market has long been regarded as the origin of mainstream luxury goods and includes firms like Ferragamo, Prada, Gucci just to name a few. With a rich cultural heritage embedded within their brands, these Italian firms have captured loyal customers and remarkable profits from all over the world. In Italy, luxury firms are deeply rooted in their design, quality, artisanship and service and it has often taken decades to build their reputation. These features often appeal to the Chinese investors. This paper presents a cross-case analysis based on case-studies of two Chinese acquisitions to provide some in-depth insights into the postacquisition integration strategies implemented by the Chinese investors in the luxury Made in Italy sector. Both the case-studies explore the distinctive challenges that both the Chinese investors and the acquired Italian firms inevitably have to face. The paper comprises six sections. The first section provides an introduction covering the 
background of the research and outlines its rationale. While the second section reviews the relevant literature, the third section provides a description of the methodology adopted. The fourth and the fifth sections present the two case-studies and the cross-case analysis respectively. The original contributions of the research and directions for further research are discussed in the concluding section of the paper.

\section{OFDI from emerging countries}

The Chinese acquisitions affecting the Italian manufacturing sector are emblematic of a wider trend. Many emerging economies have benefited from a massive infusion of capital, technology and managerial expertise from the traditional industrialized countries (Rios-Morales and Brennan, 2010). Because of this and other factors, firms in some of these countries have amassed sufficient capital, knowledge and know-how to invest abroad on their own. The proportion of FDI accounted for by NICs is increasing. A variety of reasons has been offered for the emergence of FDI from NICs (Rios-Morales and Brennan, 2010). These include the support of exports, the expansion of market presence, the acquisition of established brands and foreign skills and the establishment and strengthening of local distribution networks. The increasing financial strength and the growing international exposure of companies from NICs together with greater domestic competition have also been suggested as explanations. Finally, the goals of building international brands, accessing advanced technologies and establishing R\&D centres in developed countries help to explain this growing trend.

The surge of FDI in recent years has generated a growing body of literature on FDI with the theory of internationalisation and the Eclectic Paradigm widely utilized. The theory affirms that the extent and pattern of international production undertaken by MNCs is determined by the interaction of three sets of interdependent variables: Ownership, Localization and Internalization advantages, resulting in the abbreviation and alternative name of the eclectic paradigm, namely the OLI paradigm (Dunning, 2006). The first competitive advantage represents the ownership $(\mathrm{O})$ of specific resources to be exploited externally. The second element of the OLI paradigm regards the host country location attractiveness (L). Rugman (1981) defines the L-advantage as the Country Specific Advantage (CSA) that is unique to the business in each country. With regard to the last variable of the paradigm, the internalization (I) advantages involve the opportunity to keep firm specific resources within the company rather than to exploit them in the market through arm's length transactions (Amighini et al., 2010). The OLI variables explain why internationalization occurs but do not identify the process of internationalization. Thus, the eclectic paradigm has been subsequently extended to include the theory of the Investment Development Path (IDP) that was first put forward in 1975 and since then it has gone through various iterations (Dunning, 1981, 2006; Dunning and Narula, 1996). According to this theory, companies engage in FDI not only to exploit their existing $\mathrm{O}$-advantage in a host location, but also to augment the advantages by acquiring complementary assets or new markets (Dunning, 2006). Both theories identify the institutional environment as one key factors for internationalization, however, the focus is generally on the recipient country only.

\subsection{OFDI from China: Post-Acquisition Integration Strategies}

In the context of MNCs from NICs, China represents the second leading players among all economies in terms of OFDI flows, after the US (UNCTAD, 2015). While China's dominant position as a recipient of global FDI flows has been well documented, the overseas investment activities of Chinese companies have received considerably less attention (Vecchi \& Brennan, 2014; Vecchi, 2016). However, a recent wave of cross-border acquisitions by Chinese firms has brought increased interest to this topic. In this age of financial crisis and austerity, an increasing number of European luxury companies are seeking financial support and alliances with wealthy companies. The result is that Europe is experiencing a structural wave of Chinese MNCs acquisitions where annual inflows tripled from 2006 to 2009, and tripled again by 2011 to $€ 10$ billion for 2012 (Rhodium Group, 2012). Subsequently, China's outbound acquisitions in the West has been growing at a record pace, as more and more major American and European companies are strategically being bought up by Chinese enterprises (Forbes, 2016). Chinese acquisitions in the EU accounted for $€ 14$ billion in 2014. For the period 2000 to 2014 over 1,000 Chinese greenfield projects and acquisitions took place in the EU together worth more than $€ 46$ billion (Rhodium Group, 2015). According to a recent report by the Mergermarket Group, China had already surpassed its yearly record for outbound M\&A investment by the end of August 2016. With 173 deals worth $€ 120.4$ billion, China has been the top acquirer of foreign companies in 2016 - a position which unseat the USA for the first time since 2006 (Mergermarket Group, 2016). The sectors that attracted the most Chinese capital are energy, automotive, food and real estate. State-owned companies play an important role in China's investments in Europe, but growth in

2523-6547 - Copyright: (C) 2017 The Authors. This is an open access article distributed under the terms of the Creative Commons Attribution License, which permits unrestricted use, distribution, and reproduction in any medium, provided the original author and source are credited. 
recent years is mostly driven by private companies and financial investors from the most advanced eastern coastal provinces (Rhodium Group, 2015).

This phenomenon from its outset started rising some concerns. According to Meunier (2012: iii) in a briefing to the European Parliament 'Chinese OFDI may come with implicit strings attached and could potentially act as a Trojan Horse affecting European norms and policies, from human rights to labor laws. The surge of Chinese investment could also potentially affect European institutional processes, exerting both centrifugal and centripetal pressures on European integration'. According to Knoerich (2016), widespread criticisms of Chinese acquisitions focus on the state ownership of many acquiring firms, state backing and resulting unfair competition in global takeovers, the high levels of debt held by Chinese acquiring firms, their inexperience as latecomers in global markets, and their strong interest in acquiring technologies and strategic assets. Moreover, there are several accounts of failed acquisitions. As such, in the attempt to provide a more objective and balanced view, to the purpose of this research it is useful to identify the post-acquisition integration strategies implemented by the Chinese investors as they have been identified by the existing literature on the subject.

In terms of internationalization drivers, Mathews (2002) has developed a theoretical framework called Linkage, Leverage and Learning (LLL) to analyze the phenomenon of the EMNCs from the Asia-Pacific region - the "Dragon multinationals". The framework captures the idea that latecomers use their overseas investments and global Linkages to Leverage their cost advantages, and Learn about new sources of competitive gains. Differently from the OLI perspective (Dunning, 2006), Mathews sees the first phase of EMNCs formation as most likely to begin with asset-exploring purposes rather than asset-exploiting motives. He argues that linking with mature market MNCs, a latecomer firm may leverage knowledge, technology and market access with the result of entering in a learning process, which can be then exploited for further growth (Mathews, 2006). According to the LLL model, the degree of international success is related to the extent to which links can be established and resources can be leveraged. The potential advantage is related to the accessibility to these resources in terms of their inimitability, transferability or substitutability. The benefits depend both on the ability of the firms to leverage external resources and on their 'absorptive capacity' that is their ability to identify, assimilate and exploit external knowledge (Cohen and Levinthal, 1990).

Barkema et al. (1996) in particular, found that in this process firms face cultural adjustment costs, especially when they engage in "double layered acculturation" such as in the cases of M\&As. However, the authors show that internationalizing firms can move down the learning curve in such acquisitions, especially when they choose their expansion path so that they can exploit previous experience in the same country or in other countries with similar cultural characteristics. On the contrary, Morosini et al. (1998) outline that national cultural distance enhances cross-border acquisition performance by providing access to the target's and/or the acquirer's set of routines and repertoires embedded in national culture. Within the context of Chinese acquisitions, Bjorkman et al. (2007) propose that cultural differences can be both an asset and a liability - they can be beneficial as they may enhance potential synergies, but they can also create obstacles to fully reaping the benefits of the acquisition by exacerbating social integration problems and thus diminishing the acquiring and acquired firms' capacity to mutually absorb capabilities from each other. Luo and Tung (2007) argue that when undertaking international expansion, EMNCs face some distinctive challenges including of their poor corporate governance, the need to manage and integrate their rapidly expanding international footprint, their lack of global experience, and their weak product/process innovation capabilities.

Williamson and Anand, (2013) show how Chinese firms can upgrade by acquiring advanced economy firms and by assimilating their capabilities. Studies frequently claim that acquiring advanced or higher order capabilities such as innovation capability is a motivation for Chinese firm acquisitions (Deng, 2009; Luo and Tung, 2007). The evidence on acquisitions of advanced economy targets enabling Chinese firms to upgrade their capabilities however is very limited and is anecdotal or case based. Case-studies show that many acquisitions of advanced economy firms have failed (Williamson and Anand, 2013). Some studies find anecdotal evidence of Chinese firms upgrading their production capabilities aided by their acquisitions of advanced economy firms (Ramamurti and Singh, 2009; Williamson \& Anand, 2013). There is however no evidence of innovation capability upgrading. Although Chinese firms do indeed obtain patents and technological products of target firms, what Williamson and Anand (2013: 276) call "hard technology and intellectual property" through acquisitions, gaining ownership of existing patents and products is not the same as gaining the capability to innovate new-to-the-world products and processes (Chari, 2015).

2523-6547 - Copyright: (C) 2017 The Authors. This is an open access article distributed under the terms of the Creative Commons Attribution License, which permits unrestricted use, distribution, and reproduction in any medium, provided the original author and source are credited. 
According to Brennan (2015), the greatest challenge facing Chinese acquisitions in Europe is adjusting their style of organizing and of managing their operations from their traditional hierarchical mode of organization, as well as the command-and-control based approach to management, to one that is more compatible with the more autonomous work culture prevalent in Europe. Chinese acquirers that tend to be more successful in Europe have largely adopted a hands-off approach to the acquired entity; those that have not adjusted their style of management tend to face challenges, such as the loss of key human capital, as well as related reputational capital. Navigating the very different cultural and institutional environment in Europe and operating according to local norms and practices requires preparation and training for Chinese managers. An additional challenge for Chinese investors in Europe relates to their need to develop their absorptive capacities if they are to fully reap the benefits from the know-how and capabilities of the acquired entities.

Haspeslagh and Jemison (1991) consider that the success of an acquisition strongly depends on the successful integration of the two organizations following the acquisition, with the choice of integration type being based on two essential criteria: the interdependence between the entities, and the target's need for organizational autonomy. Combining these two criteria helps to identify a number of ideal-typical integration modes. The first one is absorption, which is intended to quickly align the target's strategies and practices with the acquirer's and results in significant changes in the structure and the systems of the target. The second approach is preservation, which allows the target's strategies and organization to be maintained, since changes are restricted to an absolute minimum. In practice, there is a continuum between absorption and preservation, more than a binary choice between two distinct categories. The third approach is symbiosis, which aims for the target and the acquirer to learn from each other and share their qualities. The three modalities suggest three different integration modes. Absorption represents a high level of integration. It means dissolving the boundary between the acquiring and acquired firm and minimizing autonomy of the acquired management. Symbiosis indicates a moderate level of integration, where the acquiring and the acquired firms co-exist and gradually become interdependent. Preservation witnesses the lowest level of integration, in which the acquisition is managed at arm's length, thus the highest autonomy for the acquired management.

Weber et al. (2009) revisited Haspeslagh and Jemison's (1991) framework and integrated the cultural-specific dimension into the integration mode. They explain the level of integration by emphasizing that not only the cultural differences can influence the integration mode but also cultural-specific dimensions. The theoretical model presented by the authors explains how the specific national cultural traits of the acquirer should be related to its choice of integration approaches. According to this interpretation each acquirer should consider not only the synergy potential and the implementation difficulties due to cultural differences, but also the acquirer's preferences for level of integration based on cultural dimensions and traits, within the integration approach that was chosen for the M\&A.

As for the integration strategies implemented by Chinese firms, Child and Rodriguez (2005) show that the apparent preference of Chinese firms when investing abroad to rely on acquisitions and organic growth rather than joint ventures with non-Chinese MNCs suggests that they may prefer to retain their distinctive administrative heritage. Fortanier and Van Tulder (2008) compare the pattern of international expansion of large firms from China with those from developed countries. They find that Chinese firms have internationalised more rapidly and more recently and tend to present a more volatile trajectory of internationalization vis-à-vis those in developed countries.

Deng (2009) argues that Chinese firms possess firm-specific assets that give them competitive advantages at home and seek complementary strategic assets that are more advanced through their acquisitions abroad. The partnering approach to post-acquisition integration helps secure these strategic assets by giving autonomy to the target firm's management team, retaining talents and creating synergy. Similarly, Kale and Singh (2012) assume that Chinese firms would prefer to develop an integration approach based on partnering, characterized by a high level of autonomy left to the acquired entities and a selective coordination of activities with the acquirer. This partnering approach developed by Chinese firms is likely to change over time. As they become more and more experienced, Chinese firms may develop more interventionist approaches. In similar fashion, according to Marchand (2015) "classical" DMNCs usually develop an absorption type of integration, whereas Chinese firms use mainly the partnering approach: they would not absorb their acquisitions, rather collaborating with them. The partnering integration mode, which is close to a strategic alliance, would be, if not completely distinctive, at least a recurring feature of Chinese firms and manifests itself through several features: structural separation of the acquired entity, selective coordination of activities between the two entities, few replacements of the target's resources (management team, brands), high organizational autonomy left to the target, and a gradual integration speed.

2523-6547 - Copyright: (C) 2017 The Authors. This is an open access article distributed under the terms of the Creative Commons Attribution License, which permits unrestricted use, distribution, and reproduction in any medium, provided the original author and source are credited. 
Liu and Woywode (2013) propose a post-acquisition integration framework that identifies synergy potential (strategic intent and industry complementarity), cultural influences (cultural differences and cultural specific dimensions) and absorptive capacity (individual and organizational) as explanatory antecedents to the chosen integration approach. By blending several theoretical lenses, they extend the revised model of integration mode (Weber et al., 2009) and add one important element, which is learning perspective. In particular, they believe that the level of absorptive capacity that an organization possesses will be a good predictor of the integration strategy chosen. Within this context, the light-touch approach is an integration of preservation and symbiotic approach.

In the light of these features, according to Knoerich (2016), for many of the target companies, Chinese acquirers are distinctively appealing in several respects. In particular, many target firms have identified a set of complementarities between the motives driving Chinese acquisitions and their own strategic objectives, and wish to capitalize on these complementarities. For example, many target firms require the assistance of their Chinese counterparts to gain better access to the lucrative Chinese market. In most sectors, a presence in the Chinese market is nowadays necessary for success and survival, however approaching and managing this market without local support can be difficult. In exchange, target firms offer their own international experience to support the internationalization of their Chinese counterparts' businesses. Similarly, some target firms welcome the support of their acquirers in cost-reduction efforts, aiming to broaden the market segments in which they are cost competitive. In turn, target firms are often willing to transfer know-how and technology to the investors and offer to engage with them in joint efforts at research and development. This may be a step toward fulfilling the objective of the Chinese investors to gain strategic assets and upgrade their products, allowing them to enter higher-end segments than they have previously occupied in both international and Chinese markets.

In addition, target firms often value the injection of capital by Chinese acquirers, either because they are in dire need of funds to avoid bankruptcy or further to expand their businesses. Chinese companies are attractive bidders because they are often rich in cash either from profits made in the lucrative Chinese market or as a result of state support. The attractiveness of these deals to target firms is often further enhanced by the maintenance of a strong separation between them and the acquiring firms, following a "light-touch" post-acquisition integration strategy (Liu \& Woywode, 2013). Under this approach, target firms are able to keep their identity and organizational structure and to continue business at their original locations, with most decisions still made by their own management. This strategy helps to mitigate concerns about the potential undesired loss of know-how and reduces other apprehensions about Chinese investors.

\subsection{Chinese acquisitions in the Italian manufacturing sector}

The scenario of Italy and China is particularly interesting due to the peculiarity of the Italian economic system which shares some features with the Chinese one. These are namely the strong presence of Small and Mediumsized Enterprises (SMEs) that are specialized in traditional manufacturing industries (Rabellotti and Sanfilippo, 2008; Amighini et al., 2010). A recent study (Pietrobelli et al., 2010) shows that Chinese firms often regard Italy as a particularly informative European market since the consumers' taste is often perceived as being very demanding and very sophisticated. Moreover, in mainland China, Italy's reputation for high quality and premium products remains strong and the market for luxury goods has experienced remarkable growth (The Economist, 17/03/2012). According to Filippov and Saebi (2008), Chinese investments in Italy reflect the effort to enter competitive European markets and obtain access to superior technologies, know-how and capabilities. The high level of specialization in sectors such as the automotive, textile and clothing, machinery and home appliances represents a very appealing factor for China wishing to upgrade its production and technological capabilities and build its own global champions in these industries (Mariotti and Mutinelli, 2008).

According to a report from the Rhodium Group (2012), the first Chinese investment in Italy was in 1986 when Air China opened a commercial office in Rome and until the end of the 1990s the number of investments from China was negligible. However, since 2000 the number of Chinese acquistions in Italy has increased significantly as a confirmation of the importance of the strategic asset seeking motivation. Pietrobelli et al. (2010) affirm that what is happening today in Italy resembles the "Marco Polo effect" that happened in China centuries ago but in the opposite direction. At that time, Marco Polo was impressed by the level of civilization achieved in China and brought back to Italy some important scientific and technological discoveries. The same is happening today, since Chinese companies seem to be interested in gaining the knowledge and the expertise developed in Italy, in particular in the luxury sector which is design-intensive and characterised by high-quality production. For these reasons, Chinese MNEs are increasingly targeting the acquisition of technological skills, design capabilities and brands that are available in the Italian specialized manufacturing clusters (Pietrobelli et al., 2010).

2523-6547 - Copyright: (C) 2017 The Authors. This is an open access article distributed under the terms of the Creative Commons Attribution License, which permits unrestricted use, distribution, and reproduction in any medium, provided the original author and source are credited. 
Rather than building home-grown brands that would require a long time to become established, Chinese firms seek to invest in Italian brands that possess a rich heritage but have fallen on hard times or gone out of fashion to consolidate their position in the global market. An emblematic example is the acquisition of Omas, a company specialized in the production of luxury fountain pens since 1925, which was acquired in 2007 by the group Xinyu Hengdeli Holdings. Other cases are the Hembly International Holdings, a leading Asian clothing retailing group that acquired Sergio Tacchini, a well-known but declined luxury clothing brand in 2007 and Trendy International, a Hong Kong clothing distributor who recently bought a minority stake in Miss Sixty, a popular luxury clothing manufacturer for teens. Overall, the widespread anxiety concerning China's international expansion calls for a better understanding and knowledge of the strategies of Chinese companies entering the Italian luxury market to better inform what is becoming an increasingly important debate. Although this topic is becoming fashionable in international business studies, the empirical evidence on Chinese FDI in European countries is quite limited and mainly relates to the UK (Burghart and Rossi, 2009; Cross and Voss, 2008; Liu and Tian, 2008) and Germany (Schüller and Turner, 2005). This evidence is even scarcer if we consider Italy and to large extent the luxury manufacturing sector.

An exception to this lack of evidence is a study conducted by Spigarelli and colleagues (2013). Spigarelli et al. (2013) illustrate how Chinese companies use Italy to access Western markets (and strategic logistical services), as well as a wide range of distinct skills/intangible assets, such as brands, know-how and technology, particularly in the manufacturing industries. The findings suggest that while superficial product portfolio and cost benefits can accrue due to the acquisition, cultural and administrative differences and lack of synergies between the two companies prevented the acquirer from fully integrating the intangible assets, particularly human resource talent, of the acquired firm. Given such limited evidence, there is a valuable opportunity to conduct further research.

\section{Methodology}

This paper presents the results of two case-studies of Chinese acquisitions that were conducted to provide some in-depth insights into the post-acquisition integration strategies implemented by these firms in the Italian luxury sector. The paper relies on two in-depth case-studies (Yin, 2008) that were purposefully chosen to illustrate some distinctive challenges that were faced by both the target and the acquirer firms during the implementation of their post-acquisition integration strategies. The acquisitions that were selected were namely the acquisition Meneghetti by Haier in 2001 and the acquisition of Benelli by Qianjiang Ltd in 2005. The acquired firms are both luxury firms that operate in a niche luxury sector and they all enjoy a long history and traditions and can be considered as being representative of the luxury Made in Italy due to their design-intensive nature and the premium quality of their products.

2523-6547 - Copyright: (C) 2017 The Authors. This is an open access article distributed under the terms of the Creative Commons Attribution License, which permits unrestricted use, distribution, and reproduction in any medium, provided the original author and source are credited. 
Additionally, to increase comparability and confidence in the findings, the two case-studies followed a structured research protocol (Baxter and Jack, 2008) as illustrated in Table 1 below. Apart from secondary research in the form of media reports and company documentation, primary research was carried out via interviews. These indepth interviews were conducted with four top executives and with a range of other six key informants who were knowledgeable about the acquisitions to validate the findings.

\begin{tabular}{|c|c|c|}
\hline \multicolumn{3}{|c|}{ Table 1: Case-study research protocol } \\
\hline Data Source & \multicolumn{2}{|c|}{ Main Focus } \\
\hline \multirow{3}{*}{$\begin{array}{c}\text { 1 In-depth interview with } \\
\text { Meneghetti General Manager } \\
1 \text { In-depth interview with Benelli } \\
\text { CFO }\end{array}$} & Overview of the target's market & Overview of the acquirer's market \\
\hline & Brief history of the target & Brief history of the acquirer \\
\hline & Target's main strategic assets & Acquirer's main strategic assets \\
\hline \multirow{4}{*}{$\begin{array}{c}\text { Media reports } \\
\text { Companies' documentation }\end{array}$} & & Acquirer's international expansion \\
\hline & \multicolumn{2}{|c|}{ The acquisition } \\
\hline & \multicolumn{2}{|c|}{ The post-acquisition } \\
\hline & \multicolumn{2}{|c|}{ The integration phase } \\
\hline $\begin{array}{l}6 \text { In-depth interviews with key- } \\
\text { informants }\end{array}$ & \multicolumn{2}{|c|}{$\begin{array}{l}\text { Discussion of the findings to increase both their validity and their } \\
\text { robustness robustness }\end{array}$} \\
\hline
\end{tabular}

First, the General Manager of Meneghetti and the Financial Officer of Benelli were interviewed to investigate some aspects of the acquisitions that would not have emerged with other data collection methods. Both the interviewees have been working in their respective companies for many years and played a crucial role before, during and after the acquisition. The interviewees also provided useful material such as financial reports of the companies along with other secondary data that were useful to corroborate the findings (Baxter and Jack, 2008). Additionally, to overcome the limitations that conducting four purposefully chosen case-studies entail (Yin, 1984), and to increase the robustness of the findings six key informants possessing relevant expertise in the field and knowledgeable about the acquisitions were also interviewed (Tellis, 1997). The data collected from the four main interviews and the six interviews with the key-informants was cross-referenced with secondary data from company material (e.g. official press releases, companies' bulletins, companies' websites) for triangulation (Jick, 1979).

\section{Findings}

\subsection{The acquisition of Meneghetti by Haier}

\section{The Target.}

Founded in 1960, Meneghetti SpA is a family company producing domestic appliance components, such as cooking hobs and ovens, under third parties' renowned brands. In the late 90s, the business was particularly committed to the production of the so-called 'mini-kitchen'. The mini-kitchen was meant as a compact selfcontained kitchen designed to fit small spaces. The design included, in addition to the structure, built-in cooking hobs, an oven and a small refrigerator. Since the in-house production was already covering the cooking hobs and the ovens, Mr Meneghetti decided to start manufacturing the refrigerator unit as well. In the late 90s, he inaugurated a new refrigerator plant in Campodoro, near the city of Padua, not far from the original plant based in Rosà (in Vicenza). Unfortunately, later in the same year, Mr Meneghetti, the charismatic innovator and leader of the company, passed away leaving the management to the heirs. In 2001, the Meneghetti family decided to retain the core business of the family and to sell the refrigerator plant in Campodoro to the Chinese Qingdao Haier 
Co., Ltd maintaining an $8 \%$ share ownership. The facility's production capacity was 250,000 units per years and at the time, the facility employed 100 people (Yi and Ye, 2003).

\section{The Acquirer.}

Qingdao Haier Co., Ltd. is a company specialized in manufacturing and distributing household appliances and consumer electronics goods. Based in Qingdao, China, it currently owns 24 manufacturing centres, 21 industrial parks, and 5 R\&D centres in Europe, North America, Asia, the Middle East and Africa. Controlled with a share holding of $45.9 \%$ by Haier Group Corporation, a privately held company characterized by large state-owned stakes, Qingdao Haier Co., Ltd. has been listed on the Shanghai Stock Exchange since 1999. Originally named Qingdao Refrigerator Co., Ltd., Haier was founded in 1984. As happened to many Chinese companies, Haier business growth and development has been shaped by Chinese historical and political milestones of the post-Mao era. In particular, the company has some experience in terms of collaboration with DMNCs having signed a jointventure contract in 1985 with the German company Liebherr. Throughout this alliance the company, whose name changed to Haier, acquired equipment and technology know-how from the German counterpart managing to boost expansion within the national market. The use of a shared trademark was a great help to win market share since the foreign brand reputation conveyed an idea of prestige and quality to the Chinese customers (Yi and Ye, 2003). By the end of the 90s, the Chinese market for refrigerators was incredibly promising and fast growing. Social acceptance of private property and increases in per-capita incomes were the main drivers of household appliance sales in China. The refrigerator was the first electrical appliance that a family wanted to own and the symbol of a whole new revolution - not just a status symbol but the appliance that changed the traditional way of storing and consuming food and beverage. During this phase, Haier started to pursue a differentiation strategy and aggressively expand internationally. Haier's aim was to become a truly global player, by increasing its market shares and by building a worldwide brand. To fulfil this goal, the initial strategy adopted was to first penetrate the difficult markets and later on focus on the easier ones. The most challenging and profitable markets were the US and the European ones. In Europe, the European customers had always been generally considered quite sophisticated and, most importantly, the market was extremely fragmented - a product appealing to the British taste possibly did not appeal to the Spanish. Therefore, gaining success in the European market meant that Haier needed what it takes to win the global market. The development of the European strategy started with an initial joint venture with Philips in Netherlands and later on through acquisitions and the establishment of commercial outposts in all the major markets (e.g. France, the UK, Spain, Germany, Poland, Greece, Russia). Nowadays, Haier's production strategy is blended. Part of its manufacturing is made in China and part of it is localized in local markets. The rationale of this blended strategy is to establish a "locally designed, locally made and locally sold" system that allows Haier to acquire the latest information and understand the changes in local customers' demands (Kumar and Steenkamp, 2013). In addition to the capability of quick reactions to market changes, producing locally allows Haier to put 'Made in the US' or 'Made in Italy' labels, avoiding in this way the customer perception of low quality exports from China. Haier products are sold through most major retail chains. Considering the refrigerator business, Haier pursues a differentiation strategy in China and in the US through the Casarte brand, targeting high margin price segments, whereas in Europe and in Italy the products are targeted to medium margin price segments like the ones from the main competitors such as Candy, Merloni and Indesit. However, brands such as Borsch, Liebhers and Siemens are still preferred by European consumers due to a strong preference towards European brands. The latter issue has posed one of the biggest challenges for Haier - build satisfactory products for customers getting more and more sophisticated and at the same time overcome the drawbacks linked to common prejudices and misconceptions over Chinese brands.

\section{The Acquisition.}

Having decided to go global, Haier's first strategy to approach the European market was to send sales representatives knocking the office doors of the most important retailers (e.g. Carrefour, Conforama, El Corte Inglés, Kingfisher) to introduce and place their products. According to the General Manager of Meneghetti, the approach was not very effective. Sales representatives were not fluent in English, the catalogues were most of the time in Chinese and the product itself unappealing to the European taste. The refrigerators that were selling so well in China and that were reporting fair success in the US were almost impossible to place in the European market because they were considered 'ugly'(Interview with the General manager). In addition, the label "Made in China" was creating the wrong expectations - the product was supposed to be extremely cheap and only adequately functional. It was during this phase that Haier was approached by Mares Marketing. Mares Marketing, a company based in Varese, specialized in offering sales and marketing services to manufacturers of domestic appliances in need of expertise to develop their sales network in the European market. In early 2000s, it was the

2523-6547 - Copyright: (C) 2017 The Authors. This is an open access article distributed under the terms of the Creative Commons Attribution License, which permits unrestricted use, distribution, and reproduction in any medium, provided the original author and source are credited. 
founder manager of Mares Marketing that put in contact the heirs of the late Meneghetti and the Haier managers to promote the acquisition of the refrigerator plant in Campodoro. In July 2001, the official announcement was released: Qingdao Haier Co. purchased the Italian refrigerator plant belonging to Meneghetti spa, based in Campodoro, for USD 8 million. The new-born entity was named Haier (Italy) Appliances. The acquisition was meant to mark a turning point in Haier expansion. The inaugural celebration was delivered in Chinese style. Haier management explained the mission and the vision for the future, the traditional ribbon was cut, Italian and Chinese flags were waved in the air. In the meanwhile, all employees listened carefully somehow astonished by the nationality of the ownership but mainly relived that the future now appeared less uncertain. However, Haier's euphoria for the conclusion of the first European acquisition rapidly burnt out when the deal revealed itself not to be as good as expected. The facilities were surely new but the refrigerator production had never been properly launched, therefore since the customer portfolio was without any orders there was a clear production overcapacity. The Chinese management team sent to Italy consisted of just one production director and an interpreter (Interview with the General manager).

\section{The Post-Acquisition.}

At the beginning, the difficulties were several. Irregular production orders, incommunicability between managers and workers, and finally chaos generated by the whole 'cassa integrazione' situation. 'Cassa integrazione' is a sort of an unemployment insurance that companies facing financial difficulties can resort to. It means that for a fixed number of days in a year workers do not come to work but are still paid by the company for these working days lost. In so doing, the company still saves money by making reduced payments towards National Insurance and Stamp contributions and still guarantees employment and workers' rights. From the Chinese standpoint it was unbelievable that workers were to be paid for not working and staying home, the Chinese managers did prefer to keep them in the factory even if there was no production. From 2001 to 2003, nothing relevant happened in the Italian subsidiary. Haier kept expanding in Europe through the opening of regional commercial centres, each one independent from the others, with their own product manager, accounting and logistics departments and one production director to achieve the budget. The headquarter for the Haier European commercial area was located in Paris. In Italy, the regional centre was originally based in Varese and later on in Milan. In the meantime, the Campodoro facility was only marginally involved in the greater strategy. According to the General Manager, at that time the plant was seen more as a burden than a resource to be exploited (Interview with the General manager). Things started to change by the end of 2003. The Qingdao management realized that the Italian plant could be used as a regional observatory to observe the market, the product itself, the competitors' price dynamics, the suppliers' networks and all the production information that were not usually available through the commercial salesmen. The responsibility to supervise the plant was given to the General Manager of Meneghetti, a very reputable Italian manager with extensive experience in the sector having previously worked extensively in Zanussi, Electrolux and Whirlpool. When considering Haier's acquisition of Meneghetti, it can be said that from 2001 to 2004, the Chinese management of Haier Italy Appliances was more concerned with minimizing the damages rather than proactively starting a proper post-acquisition strategy (Interview with key-informant A). At that time, the production consisted of the assembly of a double-door refrigerator (with a refrigerator and a freezer integrated in the same appliance) of Chinese design that in Europe targeted the lower end of the market. The profit margins expected were almost impossible to achieve. Acquiring the relevant management expertise, in the person of the General Manager, was the first step made by Haier to change the status quo of the forgotten Italian plant. During the following four years, the Italian management (the General Manager and his team) and the Chinese chief engineer in Qingdao, the only one truly believing in the potential of the Campodoro plant, jointly conceived the product that marked the turning point for Haier's expansion - the 3D refrigerator. The product was totally designed from scratch for the European consumers, it was innovative from a technological standpoint, functional, and 'beautiful to look at since its design was refined and sleek' (interview with the General Manager). Unsurprisingly, the 3D refrigerator became the Haier ambassador product in Europe, registering great success also in China, where the 'Made in Italy' label greatly appealed to wealthy consumers. The Campodoro facility became the production centre of the new product. Even though Italian wages were costly by Chinese standards, the product was meant to target the high end of the market, therefore the profit margins were possible to achieve. In the Campodoro facility, the production line was modernized to match the needs of the new design, maximize process and product communalities and minimize process bottlenecks and inventory. In 2009, the Campodoro plant worked at its full capacity with a yearly production of 80-100,000 units (Interview with the General Manager). The factory was not just an assembly facility, it purchased the painted foils and the manufacturing was entirely made in-house. Since the plant was relatively small - competitors had more than one production line and production of 1 million units per year, the economies of scale were more difficult to obtain. This provided the rationale for sourcing components from China where the prices were lower and where a further discount could be

2523-6547 - Copyright: (C) 2017 The Authors. This is an open access article distributed under the terms of the Creative Commons Attribution License, which permits unrestricted use, distribution, and reproduction in any medium, provided the original author and source are credited. 
obtained due to Haier's bargaining power. As for decisions regarding annual production volumes, the Italian factory was subordinated directly to the Qingdao headquarters rather than the Haier Europe Trading branch. Haier Europe and Haier Italy had their own catalogue both selling products that were both manufactured by Haier Italy and some imported from Haier's Chinese factories. The 3D refrigerator soon gained the status of a global product that gained the appreciation not only from Western countries but also in China, where it became surprisingly an overwhelming success (Interview with the General Manager). Specifically for this product Haier created the brand 'Casarte' that recalled the idea of 'Italian-ness', luxury and the prestige of 'Made in Italy' products. Haier targeted wealthy Chinese, with a yearly income of over USD 1 million for the product, and priced the product at USD 100 higher than the price of similar products from the competitors. The product was well distributed and helped Haier gain remarkable visibility as a brand in Europe. Unlike other multinationals coming from emerging economies, Haier proudly owned manufacturing facilities in Italy and its products were authentic "Made in Italy" goods. Nowadays, the situation has slightly changed from the 'golden era' that can be dated from 2008 to 2012 (interview with the General Manager). The original 3D product has not been radically innovated yet and its production is slightly decreasing. The European market still represents an obstacle to Haier since the path towards its quest has been much longer than just the first step made by acquiring the production facilities in Campodoro (interview with key-informant B). The drawbacks linked to the misguided perceptions of Chinese brands are still heavily influencing the purchasing of Haier refrigerators, as the General Manager confirms 'when facing two options that are quite comparable among themselves, the consumer tends to stick with the European well-known brand rather than to opt for the Chinese one' (interview with the General Manager).

\section{The Integration Phase.}

According to the General Manager, working in China and with the Chinese managers is 'not a task for weak hearted' (interview with the General Manager). The main challenge during the integration phase concerns the fundamental differences between the Italian and the Chinese culture, not just at the organizational level but also at the national level. As it was explained by the General Manager 'I was confused at first. I did not understand the Chinese culture and the way the Chinese managers behaved. Similarly, they had the same feelings about me. The turning point happened when I started learning more about their culture and to realize that it was impossible to keep doing business as I was used to. It was essential to recognize that I was not doing just business but I was doing business with the Chinese'. When considering Chinese business behaviour, it is quite difficult to identify which are its distinctive features, as it happens for the Japanese or German firms; however, it is possible to detect some distinctive traits since Chinese business behaviour tends to be heavily influenced by the Chinese national culture (interview with key-informant D). This was confirmed by the General Manager, for instance, when he mentioned the radically different attitudes towards the concept of time when approaching a project. In the Italian organizational culture, for instance, a Gantt chart is one of the most common tools used to plan the production timeline. The drawing of the Gantt chart and the planning involved are the initial steps, the initial phase when the manager or the team identifies the adequate timeframe for the project completion, defines the milestones and the checkpoints, finds out the alternatives, the corrective plans and the possible shortcuts. Through this approach the aim is to face and solve the majority of the issues that are likely to happen during the project and to closely monitor its development from the beginning to its completion. Conversely, 'the Chinese saw the Gantt chart not as the starting point but as the final one. Once the planning was executed the paper sheet was put away and forgotten' (interview with the General Manager). Moreover, the General Manager stated that the tool itself was somehow used to please the supervisor rather than to visualize the pattern toward the completion of the project. For instance, it often happened that the Gantt chart was started from the end going backwards, with the result that everything was apparently fitting even though the rationale behind the tool was completely missed. Also the notion of contract and negotiating is different, 'I was used to the idea that when the contract was signed by both the parties that it was it, instead the Chinese approach allows for further negotiation and changes even once the contract has been signed' (interview with the General Manager). Pleasing the supervisors is another issue highlighted by the General Manager that sometimes leads to misunderstandings and organizational delays. 'In China people will never say no. You have to understand when the denial is tacit. For instance, once, it happened that something was going wrong back in the Chinese facility and from the Italian office it was impossible to understand what the whole matter was about. Since the situation was murky, I decided to book a flight and go over myself. It was clear that my Chinese colleagues were not looking forward to my arrival but rather than just explicitly telling me not to come they made up excuses. First it was that the one I wanted to talk with was on a business trip in the US, then that he was free only on a particular hour, and lastly that the plant would have been closed in the days I was planning to visit to allow employees to attend the Olympic torch passage through the city. It was probably at that time that I finally had the definitive proof and I gave up: the Olympic torch official path was not going nearby Qingdao at all. The most exhilarating fact was that while in my office in Campodoro I was wondering together

2523-6547 - Copyright: (C) 2017 The Authors. This is an open access article distributed under the terms of the Creative Commons Attribution License, which permits unrestricted use, distribution, and reproduction in any medium, provided the original author and source are credited. 
with my team what the Chinese were doing, at the same time in an office in Qingdao my colleague and his team were probably wondering why I was being so stubborn not to understand that it was a no and that I wasn't welcome' (interview with the General Manager). Similarly, the General Manager discovered that the importance of pleasing a guest sometimes could be misleading for communication. At the beginning of his experience in Haier, during the first meeting in China he was asked to give a talk to the Chinese colleagues. The room was filled up with 50 people and they were all listening carefully to what he had to say. However, he soon realized that no one understood a thing of what he was saying even if there were no complaints. From then on, he learnt to stop now and then and ask not only if they were following him but also if they were able to summarize the concepts just explained. In this way, he learnt how to improve his own speech delivery and to actually dialogue with colleagues. Language was not the only barrier to face during the integration phase. Communication as a whole is an essential issue when managing a business as wide as Haier's (interview with key-informant C). Nowadays, technology allows people to work in offices as far away as 9000 kilometres from one another without any trouble. However, within a Chinese organization it is important to make yourself known in person to your peers and breach the circle of friendship, the so called guanxi (interview with the key-informant A). According to the General Manager's experience, the Italian management devoted substantial effort into relationship networking with the Qingdao colleagues in order to develop mutual trust. The General Manager's trips to Qingdao were frequent and every time a gift from Italy was brought. However, building mutual trust and relationship is not enough to manage the relations within the organization. Haier, in particularly, even though relatively young from a Western perspective, is quite a traditional business with a very hierarchic and bureaucratic organization structure. There are too many management layers and the main consequence is that the decision process is extremely lengthy and time consuming. The leadership is overloaded and when called to decide, the decisions are inefficient due to lack of information and time. Moreover, the oppression at the top of the organization is balanced by a paralysis at the periphery where managers have very little autonomy and no recognition for their good or bad actions. According to the General Manager, things are starting to change in Haier, thanks to the efforts of the current CEO. Chinese are very ambitious when setting a goal or an objective to achieve, however, most of the time what the management forwards is not a decision but a proclamation, a poster, a dazebao. This for example caused some confusion immediately after the acquisition of Meneghetti, when the Haier delegation in Campodoro announced investments and goals but then left the management of the facility to just one Chinese manager, who did not speak either English or Italian, without implementing any of the actions in the initial statement. The tendency for ambitious proclamations without due follow up actions was also evident in the reticence of the Chinese management to further invest in the marketing and the communication campaign. This was perceived as Haier's lack of resolution to ultimately build a strong brand. When the General Manager was asked about it, he answered that Haier made significant investments in the European market, but due to delays, lengthy decisions and weak communications the $3 \mathrm{D}$ product came out a couple of years later than planned. 'At that point, in Qingdao the success of the 3D product was experienced as something to exploit not as something to leverage in order to gain even more in the future' (interview with the General Manager). In addition, when it became necessary to renew and revamp the product, it was decided to commit the restyling to the Porsche Design Centre, without even considering any of the smaller independent designers who were probably more equipped and knowledgeable about the refrigerator market. In all these circumstances, the General Manager said that the Italian team tried to influence the decisions from the headquarters but it was extremely difficult due to the organizational approach of the Chinese counterpart. Decisions were made from the top managers and the involvement of the lower managers was not always welcomed. The same was confirmed by the General Manager who stated that initially his position within the company was not clearly defined, only later due to fortuitous circumstances and personal interests he became more involved in the design of the new 3D product and he gained recognition and credibility far above and ultimately appointed General Manager.

Due to the 3D product success, the Italian facility became a flagship of Haier production in Italy. Qingdao headquarters requested some changes to make the Italian factory look "a little bit more Chinese" (interview with the General Manager). Now on the walls of the offices there are Chinese posters, a clock that gives the time in Italy and the time in China, the Haier poem and outside the building there are the Italian, the Chinese and the European flags. Interestingly, when asked whether the Italian culture was somehow absorbed by the Chinese, the General Manager affirmed that it was impossible. This is the reason why in the Campodoro facility the two cultures clearly coexist and gave birth to an integrated one (interview with the General Manager). Evident examples are the Chinese posters on the corridor wall where the Mandarin text and its Italian translation are one next to each other. However, the translation is not a literal translation but one that is more apt to the Italian culture. 'It would have been ridiculous to do otherwise. It was impossible to import the Chinese culture in our plant. However, a fundamental integration step was to take conscience of the peculiarities and the differences between

2523-6547 - Copyright: (C) 2017 The Authors. This is an open access article distributed under the terms of the Creative Commons Attribution License, which permits unrestricted use, distribution, and reproduction in any medium, provided the original author and source are credited. 
our culture and theirs and make sure that everyone respect each other' (interview with the General Manager).The following Table 2 summarises the acquisition of Meneghetti by Haier and its critical phases.

\begin{tabular}{|c|c|}
\hline The acquisition & $\begin{array}{l}\text { At the time of the acquisition, aim of Haier was to penetrate the European } \\
\text { market, one of the most challenging and profitable markets in the world. } \\
\text { Following a greenfield investment in the USA, Haier realized that acquiring an } \\
\text { already existing production plant in Europe could have been a more effective } \\
\text { strategy. The Italian Meneghetti seemed a good choice at the time - the facility } \\
\text { was located in the North of Italy, where there is strong tradition of white goods } \\
\text { manufacturing, and the previous owners were willing to close the deal rapidly } \\
\text { and at a convenient price. Owning a manufacturing plant in Italy would have } \\
\text { allowed Haier to exploit the closeness to the target market, to better understand } \\
\text { the European consumers' taste, to gain an in-depth knowledge of the suppliers' } \\
\text { networks and competitors as well as to unveil strategic information that } \\
\text { through commercial outposts were impossible to obtain. }\end{array}$ \\
\hline The post-acquisition & $\begin{array}{l}\text { During the first couple of years after the acquisition, the Italian plant was } \\
\text { treated more like a nuisance than an asset. Things started to change once a new } \\
\text { General Manager, with important previous experience in the white goods } \\
\text { sector, was appointed. The Qingdao headquarters decided to invest heavily into } \\
\text { the European market. A new 3D product was developed for the European } \\
\text { customers thanks to the synergies established among the Italian plant and the } \\
\text { Qingdao headquarters. The Italian plant was the only Haier's manufacturing } \\
\text { facility in Europe. In the Campodoro facility, new machineries were acquired } \\
\text { and the production line was modified to accommodate the production of the } \\
\text { new 3D refrigerator. Components were sourced from China. Directives } \\
\text { regarding production came directly from the Qingdao headquarters. Although } \\
\text { the product experienced remarkable success in Europe, the drawbacks } \\
\text { associated with a Chinese brand were still significant. Conversely, in emerging } \\
\text { markets and mainly in the Chinese one, the 'Made in Italy' tag on Haier } \\
\text { refrigerators proved to be very successful. }\end{array}$ \\
\hline The integration phase & $\begin{array}{l}\text { In the transition period after the acquisition, the main issues among the Chinese } \\
\text { management and the Italian facility emerged in terms of different working } \\
\text { routines and lack of communications due to language barriers. Once the Italian } \\
\text { General Manager was appointed, the cultural issues were only partially solved. } \\
\text { Differences persisted in the context of organizational relationships and } \\
\text { communication with the Chinese managers. Moreover, the Chinese firm was } \\
\text { characterized by a very highly centralized approach to the decisional process. } \\
\text { Strategies were slow to be implemented and there was a significant low level } \\
\text { of autonomy at the periphery. Different attitudes towards working practices } \\
\text { and project management tools caused delays and waste of resources in shared } \\
\text { projects. A particular focus on efficiency and short-term results was noticed. }\end{array}$ \\
\hline
\end{tabular}

2523-6547 - Copyright: (C) 2017 The Authors. This is an open access article distributed under the terms of the Creative Commons Attribution License, which permits unrestricted use, distribution, and reproduction in any medium, provided the original author and source are credited. 


\subsection{The Acquisition of Benelli by Qianjiang Ltd}

\section{The Target.}

Benelli is one of the most important Italian manufacturers of luxury motorcycles. The company has been established in Pesaro in 1911 and is currently the oldest of all European motorcycle factories in operation. The company has been always family-run and has a very interesting history, having survived both World War I and World War II. It did very well until the 1960s when it entered a profound crisis due to the arrival of Japanese manufacturers, which caused a crisis in the entire European motorcycle industry. In 1995 it was initially bought by the Indesit Group that attempted to relaunch it. Despite this effort, the need for sizeable investments and the enormous financial difficulties led the company into liquidation. Following an intense period of negotiations, in 2005 Benelli was acquired by Qianjiang Ltd (QJ).

\section{The Acquirer.}

QJ is a large-scale state-owned group producing motorcycles, and one of the 520 state enterprises certified by the Chinese State Council, which focuses on the low price segment of the market and has several typical Chinesestyle low-power motorcycles (MOFCOM, 2011). The company is "dedicated to a combination of European design, Japanese quality and Chinese costs" (Spigarelli et al., 2012). The QJ Group was established in 1971 as a chemical engineering machinery factory, changed its line of production to motorcycles in May 1985 and experienced low-cost expansion and growth within a short time frame. It has been listed on the Shenzhen Stock Exchange since 1999. Only 20 percent of its production is sold abroad to markets in 110 countries. While the majority of its production tends to be low cost, the company targets the high-end segment of the market in the EU and the USA by devoting more attention to technology, brand, quality, and service. QJ has accumulated a great wealth of rich experience in product development via the building of long term collaborations with R\&D centres, leading institutes and world class experts. The Group has an exemplary quality management system (ISO9001, CE, GS, CSA, and UL standards) and has received quality licenses from national import and export product testing bureaus. QJ over the years has been engaged in many partnerships in order to upgrade its products. Currently, QJ owns two domestic brands (Cozily and Qianjiang) and three European brands (the Italian Benelli, the HungarianKeeway and a generic brand stemming from a partnership with AC, an Austrian company). With these three leading European brands, the company plans to build and expand its markets in Europe and North America, to accelerate technical innovations and to establish itself in a more competitive position in the international market (Spigarelli et al., 2012).

\section{The Acquisition.}

QJ approached Benelli for the first time in 2005. Benelli, which at the time was looking for an injection of capital, decided to sign an agreement that would help it overcome its financial constraints and at the same time benefit from QJ's main strengths, namely, its high-efficiency plants and low production costs (CFO interview). On September 16th, 2005, a deal was reached and Benelli QJ was founded. QJ acquired BenelliS.r.l. for a total of EUR 59.7 millions including the assumption of EUR 52.7 millions of debt (Benelli financial statement, 2006). QJ decided to revitalize the company by implementing a very pragmatic industrial plan by keeping the localisation of the firm in Pesaro and by keeping the entire workforce previously working in the company. Only a few staff from China were expatriated to Pesaro, these are namely the sales director, the quality manager, and the managing director. All of the technicians, workers, and engineers are Italian. An important choice made at the time by QJ was to nominate the previous CTO as the vice managing director. He was considered the "historical heart and soul of the company" (CFO interview) but he left the company in 2009, after repeated conflicts with the new managing director. All the operations related to administration, production and R\&D have been maintained in Pesaro. As pointed out by the CFO and by several interviewees, the strategic objective of the acquisition was to leverage the recognized brand, the heritage along with the knowledge of the luxury segment to penetrate a new high-premium market segment for QJ by delivering high-quality production output. "Having become aware that with two brands born from nothing they cannot produce motorcycles, QJ decided to buy Benelli so to have the technology and design and a respected brand in Europe. Essentially, they bought the history and the know-how" (Benelli's former CTO interview). Further, the QJ objective was also to use Benelli's know-how in China to increase the quality of its domestically manufactured products and to diversify its production to target a new segment. The rationale behind the acquisition was to acquire an innovative technology to more effectively counteract the fierce competition from the Japanese manufacturers in China (Benelli's former CTO interview).

\section{The Post-Acquisition.}

The first initiative after the acquisition was to bring the whole production of the engines in-house, within Benelli, whereas before the engine was developed in-house and the production was outsourced. According to the Chinese 
management, the decision to outsource the engines had been a remarkable mistake that resulted in high production costs, quality defects and ultimately leading to some inefficiency in the engines' performance (CFO interview). Now Benelli is equipped with a production line that produces 70 engines per day. This has been coupled with a significant increase of the workforce that grew from 45 to 90 employees. To this purpose, QJ signed an agreement with a local professional school involving student placements and apprenticeships. The existing suppliers were also all maintained. The technical department of Benelli QJ works closely with QJ technical department so as to capitalise on their existing potential synergies. Benelli QJ technical department in Pesaro is in charge of the design of the product, then the prototypes are sent to QJ technical department in China that is responsible jointly with the Italian division for its subsequent industrial development. Once the industrial development has been completed, the actual production takes place in Italy. The other important initiative implemented by QJ has been to significantly reduce both the production costs and the sales costs. Benelli QJ has started producing a number of secondary components in China. "We started from the simplest types of plastics components, wirings and electrical controls mounted on the handlebars. A visible shift towards cost reduction, but without affecting the quality, because the parts that require more advanced processing are still produced in Pesaro" (CFO, interview). As a result, Benelli QJ produces in China the gear-box, the throttle-body system, and balancing-shaft. "There are Italian technicians who are often in China so to support them in the production as well as in the quality control of the components"- the CFO added. "The head office often asks to borrow moulds, Italian technicians, or our engineers. Their presence is often required in China and this is a clear sign that their objective is to learn some critical phases of the production process" (CFO's interview). As for reducing the sales costs, the Italian commercial network relies on official dealers. The international distribution network is based on joint subsidiaries with Benelli and Keeway products, both brands are sold through the same distribution network but differentiated by price and quality. Overall, Benelli QJ relies on a new method of work that capitalises on the existing synergies between the two companies by leveraging their mutual strengths in order to exploit their complementarities. Benelli's motorcycling tradition, the Italian cutting-edge technology in the production of the engine and its distinctive design capabilities combined with QJ's production efficiency have resulted in new valuable opportunities for Benelli QJ to develop and introduce new models to the market. Seven new models were manufactured in the three years following the acquisition.

\section{The Integration Phase}

- After the acquisition, however some issues between QJ and Benelli emerged. In particular, cultural differences emerged in terms of staff behaviour and very different management styles. "It is very difficult to understand the behaviour of a Chinese person. For a long period, we were not able to understand why they did not give us certain answers and we wondered if it was because they could not or they did not know. After some months, we understood that they were not interested in sharing some information with us" (CFO interview). Issues related to different mind-sets, habits and also familiarity with different work environments in Italy and China soon arose in the daily routines. Communication has been a key issue, especially in the technical area. As a result of language barriers and difficulties associated with different working practices, many important projects were delayed. During the interview, the CFO for instance explained that the Italian employees were puzzled by the Chinese staff falling asleep after lunch as they were in need of a nap. This would undermine their professional credibility. Similarly the Chinese managers did not see the problem of calling to work the Italian employees on Sundays. According to the CFO, these problems stemming from mutual cross-cultural misunderstanding have significantly hindered the company's potential. Another critical issue concerned the peculiarity of the Chinese management style characterised by a great focus on efficiency. In its attempt to reduce costs QJ had to mostly cut all those investments that were characterised by less tangible returns. This rationalisation strategy resulted in reduced investment in sales promotion, marketing, and post-sales assistance without concomitantly improving the worldwide strength of the brand and the efficiency of the international distribution network. Additionally, issues emerged from the highly hierarchic approach of the Chinese management. "Each decision should be discussed with the MD and this makes us stuck and the processes are very slow. When the MD is abroad and we have to deal with urgent situations we get stuck because we cannot move without any authorization. They do not delegate anything" (CFO interview). Another issue emerged by which after a first "enthusiastic phase", human relations became somehow complicated. This was well explained by the CFO when discussing the reasons that led Mister Marconi (former CTO and then VP under QJ management) to leave Benelli in 2009. "At first, the Chinese management mainly aimed to keep Marconi, they stated that he was the heart and soul of the firm but then the management wanted to be more and more involved in any proposal of change and Marconi, missing his autonomy and his discretional power, decided to leave the firm in 2009" (CFO interview). Yet, "All the planning and control activities were mono directional" commented the interviewee. Benelli QJ does not receive any information on the strategic development plans from the QJ group or any formal and periodical feedback on its results and performances. Yet, the companies' databases are not integrated since only QJ can access Benelli's information

2523-6547 - Copyright: (C) 2017 The Authors. This is an open access article distributed under the terms of the Creative Commons Attribution License, which permits unrestricted use, distribution, and reproduction in any medium, provided the original author and source are credited. 
system. Overall, "it seems that they consider us as a pawn controlled by a world industrial giant" (CFO interview). Table 3 summarises the acquisition of Benelli by QJ and its critical phases. 
Table 3: The Acquisition of Benelli and Its Critical Phases

\begin{tabular}{|c|c|}
\hline The acquisition & $\begin{array}{l}\text { The strategic objective of the acquisition was to leverage the recognized brand, the heritage } \\
\text { along with the knowledge of the luxury segment to penetrate a new high-premium market } \\
\text { segment for QJ by delivering high-quality production output. } \\
\text { Further, the QJ objective was also to use Benelli's know-how in China to increase the quality } \\
\text { of its domestically manufactured products and to diversify its production to target a new } \\
\text { segment. } \\
\text { The rationale behind the acquisition was to acquire an innovative technology to more } \\
\text { effectively counteract the fierce competition from the Japanese manufacturers in China. }\end{array}$ \\
\hline The post-acquisition & $\begin{array}{l}\text { QJ decided to revitalize the company by implementing a very pragmatic industrial plan by } \\
\text { keeping the localisation of the firm in Pesaro and by keeping the entire workforce previously } \\
\text { working in the company. } \\
\text { The first initiative after the acquisition was to bring the whole production of the engines in- } \\
\text { house, within Benelli, whereas before the engine was developed in-house and the production } \\
\text { was outsourced. This has been coupled with a significant increase of the workforce that grew } \\
\text { from } 45 \text { to } 90 \text { employees. The existing suppliers were also all maintained. The technical } \\
\text { department of Benelli QJ works closely with QJ technical department. Benelli QJ technical } \\
\text { department in Pesaro is in charge of the design of the product, then the prototypes are sent to } \\
\text { QJ technical department in China that is responsible jointly with the Italian division for its } \\
\text { subsequent industrial development. Once the industrial development has been completed, the } \\
\text { actual production takes place in Italy. } \\
\text { The other important initiative implemented by QJ has been to significantly reduce the sales } \\
\text { costs by restructuring Benelli's distribution channels. } \\
\text { Benelli's motorcycling tradition, the Italian cutting-edge technology in the production of the } \\
\text { engine and its distinctive design capabilities combined with QJ's production efficiency have } \\
\text { resulted in new valuable opportunities for Benelli QJ to develop and introduce new models to } \\
\text { the market. }\end{array}$ \\
\hline The integration phase & $\begin{array}{l}\text { Cultural differences emerged in terms of staff behaviour and very different management styles. } \\
\text { Issues related to different mind-sets, habits and also familiarity with different work } \\
\text { environments in Italy and China soon arose in the daily routines. } \\
\text { Communication has been a key issue, especially in the technical area. As a result of language } \\
\text { barriers and difficulties associated with different working practices, many important projects } \\
\text { were delayed. } \\
\text { Another critical issue concerned the peculiarity of the Chinese management style characterised } \\
\text { by a great focus on efficiency. Additionally, issues emerged from the highly hierarchic } \\
\text { approach of the Chinese management. }\end{array}$ \\
\hline
\end{tabular}

\section{Cross-case analysis}

The two case-studies were drawn to better understand the post-acquisition integration strategies adopted by the Chinese firms. From the comparison of the two case-studies several similarities emerge.

First, both the Chinese companies at the time of the acquisitions, had affirmed themselves as top ranking players in their domestic and neighbouring markets and were looking at overseas opportunities to maintain high growth rates and increase their market shares. Moreover, at the time of the acquisitions, all companies were not at their first overseas international experience. The motives for the acquisitions were, however, different. Haier acquired Meneghetti following a market-seeking approach; unexpectedly the same product used to penetrate the European market became the most popular product in the domestic market. Differently, the acquisition of Benelli was the expression of asset-seeking approach where the Chinese company was looking to mainly acquire intangible assets such as a global brand and its heritage (interview with key-informant $\mathrm{C}$ ). Both the acquisitions are the result of a clear strategy: purchasing Italian prestigious brands as a shortcut to acquire a brand's heritage, and thanks to the injection of financial resources to re-launch the production to dominate both the European and Chinese markets. In both instances, the Chinese firms, beyond capitalising on the value of the Italian brands, tried also to benefit from a well-developed network of contacts and from the know-how stemming from the companies' long tradition

2523-6547 - Copyright: (C 2017 The Authors. This is an open access article distributed under the terms of the Creative Commons Attribution License, which permits unrestricted use, distribution, and reproduction in any medium, provided the original author and source are credited. 
in their sector. Both Chinese investors took advantage of the international reputation of the Made in Italy brands to enter new distribution channels. As for Benelli, QJ leveraged the synergies between the Chinese labour costs and the Italian technology and style to produce at lower production costs while attaining a higher market positioning and thus higher margins. In the Meneghetti case, Hayer took advantage both from its know-how and the prestige recognized by Chinese in Made in Italy brands to enhance the sales portfolio and to pave the way for the long-term brand development. Both products (Benelli's motorcycles and Meneghetti's refrigerators) rely on a specific know-how that is linked to the Italian design tradition and style. QJ, by acquiring Benelli, has largely benefited from its R\&D activities and thanks to the continuous collaboration between Chinese and Italian technicians has acquired proficiency of new technologies and of work methods. By acquiring Meneghetti, Hayer acquired a prestigious brand allowing the company to widen its own portfolio of products supporting its geographical expansion and its access to strategic distribution centres in the domestic market. Moreover, Hayer expands its customer base thanks to the appetite for Made in Italy products of more and more demanding Chinese consumers. Increased market visibility and a wide range of quality products combined with innovative designs and long tradition helped Hayer to better grasp the increasing potential of the Chinese luxury industry. In the case of both acquisitions, the Chinese investors have the opportunity to acquire all the tangible and intangible assets (such as the know-how and the local contacts) which otherwise would take them many years to be built them from scratch.

Secondly, when considering the timing of the acquisitions, some interesting peculiarities emerge. The deals are expression of the same phase of the internationalization process of Chinese MNEs. More precisely, Meneghetti (acquired in 2001) and Benelli (acquired in 2005) are examples of the export-oriented approach that China adopted in the pre-crisis period aimed at dominating European markets playing on the historic brand well-known in this sector. Both the Italian companies were facing a financial crisis at the moment of the acquisitions and they needed liquidity, and this favoured the Chinese acquisitions. Haier acquired Meneghetti in 2001, when Europe was still one of the most attractive markets. The Italian facility was sold to the Chinese acquirer when the Meneghetti family was forced to deal with the death of the founder and owner of the company, a very delicate issue in the life of a small-medium enterprise (interview with key-informant A). Benelli was acquired in 2005, a period when the economic recession was already eroding the spending capabilities of the European markets. The decision to acquire the company in this case was only partially driven by the need to enter a new market but was more linked to the idea of striking a convenient deal in the M\&A market. At the time of the acquisition, the Italian company was suffering from financial distress. In both cases, the foreign company acquisition can be considered as a shortcut, and in the case of Benelli also a convenient deal, to rapidly acquire competencies, strategic assets and market knowledge that it would have been too lengthy or impossible to build in-house (interview with key informant F).

Thirdly, in both the acquisitions, it was observed that one of the fundamental factors that acted as catalyst for the Chinese investor was the locational advantage of the company (interview with key informant A, B, D, F). All the target companies are embedded in important industrial districts. As such, they both provide a rich context characterized by a network of competences and a high concentration of intangible assets and mutually supporting relationships that can easily mitigate the liability of foreignness (Vecchi, 2008). For instance, when considering the case of Haier, the central northern area of Italy is one of the most important white goods industrial district in Europe. Similarly, Pesaro hosts several leading companies in the motorcycle sectors and their suppliers. In addition to the location advantages, it is important to emphasise how the manufacturing location becomes one of the fundamental factors when considering the brand entitlement to strategically use the Made in Italy label, whose appeal is particularly strong for emerging markets customers (interview with key-informant E).

The benefits that the Chinese firms gained from the acquisitions of tangible and intangible assets are particularly interesting to investigate in each case. On the one hand, through the acquisition of Meneghetti, Haier managed to exploit the knowledge and the proximity to the European market to develop a line of goods targeting a more sophisticated customer base. Leveraging the synergies among the internal resources of the two entities, Haier managed to achieve cost efficiencies and economies of scale in the Italian manufacturing facility that allowed supporting the higher Italian labour costs. Additionally, the Made in Italy tag associated with the new product line allowed the company to place its product in a higher market segment. The different product positioning and the consequent higher profit margins achieved have increased the visibility of the brand and attracted new sales, especially in the U.S. and in emerging markets. On the other hand, in the Benelli case, QJ took advantage of the visibility of a globally known heritage brand both to broaden its brand portfolio. In addition, with the acquisition of one of the oldest companies in the industry, QJ managed to acquire a production facility in Italy, an innovative R\&D center, a whole established network of customers and some experiential knowledge of the markets.

2523-6547 - Copyright: (C) 2017 The Authors. This is an open access article distributed under the terms of the Creative Commons Attribution License, which permits unrestricted use, distribution, and reproduction in any medium, provided the original author and source are credited. 
In order to exploit the whole set of locational advantages, the Chinese companies maintained the identity of the Italian targets by avoiding the delocalization of production in both acquisitions. As far as the post-acquisition phase, the findings highlight that the partnering approach was followed in both instances. In Haier, for instance, the integration of Meneghetti was an 'absorption strategy' where the autonomy of the Italian subsidiary is low and the degree of dependency with the Qingdao headquarters is high. QJ tried to keep Benelli's identity by maintaining the production facilities in their original location in Pesaro and by retaining its executives, workforce, and suppliers. This seems to be in line with the identification of strategic asset seeking as the main motivation of the Dragon multinationals (Pietrobelli et al, 2010). In particular, the Italian identity of the target companies was strongly preserved mainly to strategically leverage the heritage and power of the Italian brands and secondly not to confuse the final customers. Crucial when considering the level of identity preserved in the post-acquisition phase is to observe the integration strategy adopted by both the Chinese companies. Accordingly, in both cases the identity of the target company has been maintained by avoiding the delocalization of both the production and to some extent by maintaining the human resources. This is in line with the identification of strategic asset seeking as first motivation of the Chinese MNEs which aim to absorb the Western technical know-how and management skills. The findings confirm that the ongoing increase of acquisitions carried out by Chinese MNEs in the luxury Made in Italy is a signal of the strategic-asset seeking motivations where the intent is to absorb new knowledge and know-how from the target company. The analysis of the acquisitions confirms that technology, design and the prestige of a long-established brand are the main drivers. In particular, the research shows that both the acquirers sought to strengthen their competitiveness both domestically and on the international market by leveraging the design and the prestige of the Made in Italy behind the brands. However in both cases, the integration has been a long and a difficult process. Different habits and cultural background emerge in daily routines due also to differing working environments in China and Italy. On the one hand, the Chinese management is frustrated by the bureaucracy that hinders the business development. On the other hand, Italian managers are hampered by a rigid and suspicious mentality and by a highly centralized decision-making management style that can create rifts between management and employees by thus delaying the implementation of the strategy. In both acquisitions the presence of Chinese managers within the organization was temporary, mainly during the postacquisition period when in Haier a Chinese transition manager was appointed and in Benelli when they had to replace the CTO and former VP. The integration processes in the two cases were different. In the case of Haier, the integration process was long and difficult. At first, immediately after the acquisition, the daily routines and the union habits of the Italian facility caused conflicting situations with the Chinese transition manager. Later, when an experienced Italian manager was appointed, integration issues arose in the context of organizational relationships and internal communication, even though the Chinese management and the Italian one were not physically integrated in the same office. In this case, the tight contact between the two companies led to communication issues that emerged both due to different use of technical and managerial tools, different approaches to the concept of time, different notions of contract, the implicit denial and the tendency to always please the supervisor. In Benelli's experience, integration issues have concerned mostly the lack of feedback and participation in the decisional process for the subsidiary management. Both in Haier and in Benelli a a particular focus on efficiency and short-term results was pointed out by the interviewees, but this was not attributed to cultural differences but to relative lack of knowledge of the European market. In particular, it emerged that since the European market is still unknown to the headquarters they sometimes tend to compare their prior experience in other markets without taking into account the peculiarities of the European market. Interestingly in both acquisitions, the first reaction of the employees of the acquired firm to the news of the acquisition was very positive. Since at the time of the acquisitions both Italian companies were facing some delicate issues, namely the death of the founder/owner in the case of Meneghetti and some substantial lack of financial support in the case of Benelli, a new foreign investor was welcomed as positive news.

In both case-studies the positive expectations were not left unattended since both Chinese firms heavily invested in the acquired company. In Haier, for instance, the investments mainly regarded the product design of the 3D refrigerator, the launch of the new product on the European market and the renewal of the whole production facility. In Benelli the investments were aimed particularly at sustaining the delicate financial situation of the acquired company caused by the Japanese competition. However, additional resources were devoted to the R\&D department, which was duly acknowledged as the core activity for the company's ultimate success. Finally, in both case-studies the presence of a Chinese investor provided a strategic advantage against the competitors, especially the European ones, since the presence of a solid Chinese investor facilitated access to bank credit lines and the achievement of economies of scale. Moreover, having a Chinese investor meant that the Italian companies could have the opportunity to obtain access to the difficult but very large Chinese market via a privileged path, since they can capitalise on their headquarters' domestic market knowledge, their distribution channels and their networks.

2523-6547 - Copyright: (C) 2017 The Authors. This is an open access article distributed under the terms of the Creative Commons Attribution License, which permits unrestricted use, distribution, and reproduction in any medium, provided the original author and source are credited. 


\section{Conclusion}

The study contributes to the literature in many ways. First, it confirms a number of claims made in the literature on EMNCs internationalization. Second, it identifies certain nuances that are easily missed in broad theoretical studies. Third, it raises some interesting points for further research.

The paper, through both in-depth case-studies, confirms a number of claims made in theoretical studies of EMNCs international expansion, particularly into advanced economies. Specifically, the Chinese firms in all case studies confirm the expectation in Luo and Tung (2007) and in Chari (2013) that EMNCs that have secured their position in their home markets are the ones more likely to internationalize to upgrade their competitiveness. Both Haier and QJ, for instance, were well-established in their home market and nearby markets before they sought to acquire the Italian firms. Both case-studies also confirm arguments in the literature that EMNCs seek strategic assets such as brands and higher technology in their acquisitions of DMNCs (Luo and Tung, 2007; Williamson and Anand, 2013; Demirbag et al., 2010a, 2010b; Demirbag and Yaprak, 2015). The findings also tend to confirm the difficulties postulated by Barkema's "double layered acculturation" theory (1996) as well as Bjorkman's view (2007) of cultural differences more as a liability than as an asset, at least in the implementation of the postacquisition integration strategies. In particular, although in both case-studies the findings support Knoerich's view (2016) whereby the Chinese investors were welcomed by the target firms as they offered appealing complementarities, they enabled the targets to become more cost-competitive by also injecting much needed capital, significant cultural clashes tend to emerge. More precisely, the findings offer some valuable insights over the distinctive challenges faced by the Chinese investors in organizing and managing the new entity (Brennan, 2015).

For both investors have been difficult to adequately adjust their style of organizing and of managing their operations from their traditional hierarchical mode of organization, as well as the command-and-control based approach to management, to one that is more compatible with the more autonomous work culture prevalent in Italy.

In both case-studies, the Chinese investors fully embraced the partnering approach (Child and Rodriguez, 2005; Deng, 2009; Kale and Singh, 2012). They did so by pursuing structural separation, selective coordination of the activities, by having few replacements in terms of key personnel, by granting the targets high organizational autonomy as well as undertaking gradual integration speed (Marchand, 2015). Within this context, the partnering approach to post-acquisition integration helped to secure these strategic assets by giving autonomy to the target firms' management team, retaining talents and creating strategic synergies. However, the relative degree of lighttouch approach adopted is significantly different. While in the case of Benelli, the light-touch approach is clearly an integration of preservation and symbiotic approach (Liu and Woywode, 2013), in the case of Meneghetti a partial absorption strategy was implemented (Haspeslagh and Jemison, 1991). In both instances by considering the national culture of the acquirers characterized by relatively lower levels of uncertainty avoidance (i.e. China: 30 and Italy: 75) and by lower levels of individualism (i.e. China: 20 and Italy: 76) these would have been deemed as the most successful strategies by the literature (Wood et al., 2009).

From both the presence of significant cultural clashes experienced by the firms and the partnering approach implanted by the acquirers stems an interesting paradox. While according the literature on DMNCs, when the headquarters and target are not tightly integrated such issues do not arise (Stahl and Voigt, 2008), in both instances this was clearly not the case. Both case-studies showed that despite the substantial autonomy granted to the target firm, there were communication and coordination issues stemming from cultural differences. This further reinforce the argument that a fuller understanding of the post-acquisition strategies implemented by Chinese investors and more broadly by EMNCs is not only desirable but it is also a necessity.

The analysis of the two case-studies also highlighted some nuances not easily seen in broad theoretical studies, and raise some interesting research questions for the future. For example, both case-studies show that the acquisition of an DMNC's brand by an EMNC must be managed carefully in the advanced economy markets, since the low cost image of the EMNC's products can erode the value of the DMNC's brand. This is a nuance that is crucial but only finds limited support in the extant literature (e.g. Wang et al., 2012; Giuliani et al., 2014). Both case-studies for example showed how Italian and other European customers were concerned about the brand value of the Italian firm deteriorating after its purchase by Chinese firms. The case-studies also show that such erosion of brand image can be prevented, for example by carefully separating the brand identities of the DMNC from that of the EMNC through marketing, communication, and even the separation of the DMNC operations from the EMNC operations.

2523-6547 - Copyright: (C) 2017 The Authors. This is an open access article distributed under the terms of the Creative Commons Attribution License, which permits unrestricted use, distribution, and reproduction in any medium, provided the original author and source are credited. 
This separation raises an important and interesting research question. Specifically, since EMNCs acquire DMNCs at least in part to acquire their advanced capabilities, how do EMNCs acquire the capabilities while keeping the two organizations separate since a close or joint working relationship is important for the transmission of tacit capabilities (Chari, 2015). The in-depth case studies thus highlight nuances that are glossed over in broad theoretical classifications of what to expect with different types of integration strategies. In particular, more research is needed on the types of communication and coordination problems faced when DMNCs are allowed to operate largely autonomously, and the identification of strategies used to successfully address these problems.

Finally, while confirming claims in the literature that EMNCs seek advanced capabilities and brands when acquiring DMNCs, the case-studies also highlight a nuance. That is, advanced capabilities and brand image are often tied to specific locations such as the Italian industrial districts and hence EMNCs that acquire DMNCs for their strategic assets are unlikely to delocalize their production out of the target country. Even so, there may be economies of scale to be realized by sharing some production or procurement activities. Further research can shed light on how EMNCs acquirers of DMNCs balance the need to retain production in the advanced economy with the potential for scale economies from consolidating production in lower cost locations. 


\section{References}

Amighini, A., Rabellotti, R., and Sanfilippo, M. (2010). The Outward FDI from Developing Country MNEs as a Channel for Technological Catch-Up, Working Papers Print 012, Dipartimento Scienze Economiche, Universita' di Bologna.

Angwin, D. N., \& Meadows, M. (2009). The choice of insider or outsider top executives in acquired companies. Long Range Planning, 42(3), 359-389.

Athreye, S., \& Kapur, S. (2009). Introduction: The internationalization of Chinese and Indian firms-trends, motivations and strategy. Industrial and Corporate Change, 18(2): 209-221.

Barkema, H. G., Bell, J. H., \& Pennings, J. M. E. (1996). Foreign entry, cultural barriers and learning. Strategic Management Journal, 3(1):151-166.

Bauer, F., \& Matzler, K. (2014). Antecedents of M\&A success: The role of strategic complementarity, cultural fit, and degree and speed of integration. Strategic management journal, 35(2), 269-291.

Baxter, P., \& Jack, S. (2008). Qualitative case study methodology: Study design and implementation for novice researchers. The qualitative report, 13(4), 544-559.

Björkman, I., Stahl, G. K., \& Vaara, E. (2007). Cultural differences and capability transfer in cross-border acquisitions: the mediating roles of capability complementarity, absorptive capacity, and social integration. Journal of International Business Studies, 38(4): 658-672.

Björkman, I., Stahl, G. K., \& Vaara, E. (2007). Cultural differences and capability transfer in cross-border acquisitions: The mediating roles of capability complementarity, absorptive capacity, and social integration. Journal of International Business Studies, 38(4), 658-672.

Brennan, L. (2015). The challenges for Chinese FDI in Europe. Columbia FDI Perspectives, 142 (March 2nd 2015).

Burghart, N., \& Rossi, V. (2009). China's overseas direct investment in the UK. Chatham House Programme Paper IE, 2009.

Chari, M. D. R. (2013). Business groups and foreign direct investments by developing country firms: An empirical test in India. Journal of World Business, 48, 349-359.

Chari, M. D. R. (2015). An integrated model of upgrading and catchup by emerging economy firms. Advances in International Management, 28, 327-349.

Chattopadhyay, A., Batra, R., \& Ozsomer, A. (2012). The new emerging market multinationals: Four strategies for disrupting markets and building brands. McGraw Hill Professional.

Child, J., and Rodrigues, B.S. (2005) The Internationalization of Chinese Firms: A Case for Theoretical Extension? Management and Organization Review, 1(3): 381-410.

Cohen, W.M. and Levinthal, D.A. (1990), Absorptive Capacity: A New Perspective on Learning and Innovation, Administrative Science Quarterly, 35(1):128-152.

Cross, A.R. and Voss, H. (2008), Chinese direct investment in the United Kingdom: An assessment of motivations and competitiveness, presented at Corporate Strategies in the New Asia, University of Bremen, 1-2 February 2008 .

Deng, P. (2009). Why do Chinese firms tend to acquire strategic assets in international expansion?. Journal of World Business, 44(1), 74-84.

2523-6547 - Copyright: (C) 2017 The Authors. This is an open access article distributed under the terms of the Creative Commons Attribution License, which permits unrestricted use, distribution, and reproduction in any medium, provided the original author and source are credited. 
Deng, P. (2010). What determines performance of cross-border M\&As by Chinese companies? An absorptive capacity perspective. Thunderbird International Business Review, 52(6), 509-524.

Demirbag, M., McGuinness, M., \& Altay, H. (2010a). Perceptions of institutional environment and entry mode: FDI from an emerging country. Management International Review, 50(2), 207-240.

Demirbag, M., Tatoglu, E., \& Glaister, K. W. (2010b). Institutional and transaction cost determinants of Turkish MNEs' location choice. International Marketing Review, 27(3), 272-294.

Demirbag, M., Tatoglu, E., \& Glaister, K. W. (2009). Equity-based entry modes of emerging country multinationals: Lessons from Turkey. Journal of World Business, 44, 445-462.

Demirbag, M., \& Yaprak, A. (2015). Handbook of Emerging Market MNEs. Cheltenham: Edward Elgar.

Dunning J. H. (2006). Towards a New Paradigm of Development: Implications for the Determinants of International Business. Transnational Corporations, 15(1):173-227.

Dunning, J. H. (1981), Explaining the international direct investment position of countries: towards a dynamic or developmental approach, Weltwirtschaftliches Archiv, 119(1):30-64.

Dunning, J. H., Narula, R. (1996) (eds.), Foreign Direct Investment and Governments: Catalysts for Economic Restructuring, Routledge, London.

Filippov, S., \& Saebi, T. (2008). Europeanisation strategy of Chinese companies: Its perils and promises. UNUMERIT.

Forbes, (2016). China Hits Record High M\&A Investments In Western Firms. Available at: http://www.forbes.com/sites/wadeshepard/2016/09/10/from-made-in-china-to-owned-by-china-chineseenterprises-buying-up-western-companies-at-record-pace/\#6cf18dcb1387

Fortanier, F. and Van Tulder, R., (2008). Internationalization trajectories -- a cross- country comparison: Are large Chinese and Indian companies different?' UNU- Merit Working Paper \#2008-054. [http://www.merit.unu.edu/publications/wppdf/2008/wp2008-054.pdf].

Gammeltoft, P., Pradhan, J. P., \& Goldstein, A. (2010). Emerging multinationals: home and host country determinants and outcomes. International Journal of Emerging Markets, 5(3/4): 254-265.

Giuliani, E., Gorgoni, S., Günther, C., \& Rabellotti, R. (2014). Emerging versus advanced country MNEs investing in Europe: A typology of subsidiary global-local connections. International Business Review, 23(4), 680-691.

Guillen, M., \& García-Canal, E. (2012). Emerging markets rule: Growth strategies of the new global giants. McGraw Hill Professional.

Haspeslagh, P. C., \& Jemison, D. B. (1991). Managing acquisitions: Creating value through corporate renewal (Vol. 416). New York: Free Press.

Hofstede, G., (1980). Culture's Consequences: International Differences in Work-related Values, Sage, London.

Jick, T. D. (1979). Mixing qualitative and quantitative methods: Triangulation in action. Administrative science quarterly, 602-611.

Johnson, J. P., Lenartowicz, T., \& Apud, S. (2006). Cross-cultural competence in international business: Toward a definition and a model. Journal of International Business Studies, 37(4): 525-543.

Kale P., \& Singh H. (2012). Characteristics of Emerging Market Mergers and Acquisitions. In Faulkner, D., Teerikangas, S., \& Joseph, R. J. (2012). The Handbook of Mergers and Acquisitions. Oxford : Oxford University Press.

2523-6547 - Copyright: (C) 2017 The Authors. This is an open access article distributed under the terms of the Creative Commons Attribution License, which permits unrestricted use, distribution, and reproduction in any medium, provided the original author and source are credited. 
Knoerich, J. (2016). Gaining from the global ambitions of emerging economy enterprises: an analysis of the decision to sell a German firm to a Chinese acquirer. Journal of International Management, 16:177-91.

Kumar, N. \& Steenkamp, J. (2013). How Emerging Market Brands Will Go Global, Houndmills, UK: Palgrave Macmillan.

Liu, L. and Tian, Y. (2008) The internationalisation of Chinese enterprises: the analysis of the UK case, International Journal of Technology and Globalization, 4(1): 87-102.

Liu, Y., \& Woywode, M. (2013). Light-touch integration of Chinese cross-border M\&A: the influences of culture and absorptive capacity. Thunderbird International Business Review, 55 (1): 469-483.

Liou, R. S., Rose, A. S., \& Ellstrand, A. E. (2012). Emerging-market multinational corporations as agents of globalization: Conflicting institutional demands and the isomorphism of global markets. In Institutional theory in international business and management (pp. 179-206). Emerald Group Publishing Limited.

Luo, Y., \& Tung, R. L. (2007). International expansion of emerging market enterprises: A springboard perspective. Journal of International Business Studies, 38(4), 481-498.

Lyles, M., Li, D. \& Yan, H. (2014). Chinese Outward FDI Performance: The Role of Learning. Management and Marchand, M. (2015). When the South takes over the North: Dynamics of up-market integrations by emerging multinationals.M@n@gement, 18(1): 31-53.

Madhok, A., \& Keyhani, M. (2012). Acquisitions as entrepreneurship: Asymmetries, opportunities, and the internationalization of multinationals from emerging economies. Global Strategy Journal, 2(1), 26-40.

Mariotti, S., \& Mutinelli, M. (2009). Italia multinazionale 2008. Le partecipazioni italiane all'estero ed estere in Italia. Rubbettino, Soveria Mannelli.

Mathews, J. A. (2002), Dragon Multinationals- A new model for global growth, Oxford: Oxford University Press.

Mathews, J. A. (2006), Dragon multinationals: New players in 21st century globalization, Asia Pacific Journal of Management, 23(1):5-27.

Meunier, S. (2012). Political impact of Chinese foreign direct investment in the European Union on Trasatlantic relations. European Parliament Briefing Paper.

MergerMarket (2016). MergerMarket Report 2016. Available at: http://www.mergermarket.com/pdf/AsPac infographic.pdf

MOFCOM (2011), Statistical Bulletin of China's Outward Foreign Direct Investment, Ministry of Commerce, China.

Morosini, P., Shane, S., \& Singh, H. (1998). National cultural distance and cross-border acquisition performance. Journal of International Business Studies, 137-158.

Nahavandi, A., \& Malekzadeh, A. R. (1988). Acculturation in mergers and acquisitions. Academy of management review, 13(1): 79-90.

Pietrobelli, C., Rabellotti, R., \& Sanfilippo, M. (2010). The 'Marco Polo'Effect: Chinese FDI in Italy. International Economics Programme Paper, 4.

Rabbiosi, L., Elia, S., \& Bertoni, F. (2012). Acquistions by EMNCs in developed markets: An organisational learning perspective. Management International Review, 52, 193-212.

Rabellotti, R., and Sanfilippo, M. (2008). Chinese FDI in Italy. Proceedings of the Conference Emerging Multinationals: Outward Foreign Direct Investment from Emerging and Developing Economies, Copenhagen Business School, Copenhagen, 9-10 October 2008.

2523-6547 - Copyright: (C) 2017 The Authors. This is an open access article distributed under the terms of the Creative Commons Attribution License, which permits unrestricted use, distribution, and reproduction in any medium, provided the original author and source are credited. 
Ramamurti R., \& Singh J. (2009). Emerging Multinationals in Emerging Markets. Cambridge, MA: Cambridge University Press.

Rhodium Group (2012). China invests in Europe. Available at: http://rhgroup.net/wpcontent/uploads/2012/06/RHG_ChinaInvestsInEurope_June2012.pdf

Rhodium Group (2015). Chinese FDI in Europe and Germany. Preparing for a New Era of Chinese Capital. Available at: http://rhg.com/wp-content/uploads/2015/06/ChineseFDI_Europe Full.pdf

Rios-Morales, R., Brennan, L., (2010) The emergence of Chinese investment in Europe, EuroMed Journal of Business, 5(2): 215 - 231 .

Rugman, A. M. (1981). Inside the Multinationals: The Economics of Internal Markets. New York: Columbia University Press.

Rui, H., Yip, G.S. (2008). Foreign acquisitions by Chinese firms: A strategic intent perspective. Journal of World Business, 43(2):213-226.

Schuller, M., and Turner, A., (2005) Global ambitions: Chinese companies spread their wings. Journal of Current Chinese Affairs - China Aktuell, Institute of Asian Studies, GIGA German Institute of Global and Area Studies, Hamburg, 34(4):3-14.

Spigarelli, F., Alon, I., \& Mucelli, A. (2013). Chinese overseas M\&A: overcoming cultural and organisational divides. International Journal of Technological Learning, Innovation and Development 2, 6(1-2), 190-208.

Spigarelli, F., Wei, W., \& Alon, I. (2011). Benelli and QJ Compete in the International Motorbike Arena. Chinese International Investments, 355-371.

Stahl, G. K., \& Voigt, A. (2008). Do cultural differences matter in mergers and acquisitions? A tentative model and examination. Organization Science, 19(1), 160-176.

Tellis, W. (1997). Application of a case study methodology. The qualitative report, 3(3): 1-17.

The Economist, (17/3/2012). Luxury on the cheap. Chinese and other buyers snap up Italian brands. Available at http://www.economist.com/node/21550285.

UNCTAD (2011). World Investment Report. Non-Equity Modes of International Production and Development. Available at: http://www.unctad-docs.org/files/UNCTAD-WIR2011-Full-en.pdf

UNCTAD (2015). World Investment Report. Reforming International Investment Governance. Available at: http://unctad.org/en/PublicationsLibrary/wir2015_en.pdf

Vecchi, A. (2016). An Analysis of Chinese acquisitions of Made in Italy firms in the manufacturing sector. International Journal of Business and Emerging Markets (IJBEM). Vol. 8, No. 3, pp. 276-306.

Vecchi, A. \& Brennan, L. (2014). An Analysis of Chinese acquisitions of Made in Italy firms in the luxury sector. Chinese Business Review, 13(3): 192-208.

Vecchi, A. (2008). Globalisation and the Viability of Industrial Districts. Verlag Dr Muller: Saarbrucken, Germany.

Vecchi, A. (2013a). The impact of Chinese Acquisitions on the Made in Italy Luxury Sector: A systematic review of the literature. California Business Review, 1(2):39-52.

Vecchi, A. (2013b). The impact of Chinese Acquisitions on the Made in Italy Luxury Sector. Journal of International Finance and Economics, 3(2):75-82.

Vecchi, A. (2014a). Evidence from Chinese acquisitions of Made in Italy firms in the luxury sector - The acquisition of a traditional luxury firm. European Journal of Management, 14(1):113-124

2523-6547 - Copyright: (C) 2017 The Authors. This is an open access article distributed under the terms of the Creative Commons Attribution License, which permits unrestricted use, distribution, and reproduction in any medium, provided the original author and source are credited. 
Vecchi, A. (2014b). The allure of brand heritage - The Chinese acquisition of an Italian luxury pen maker. Journal of International Business and Economics, 14(1):97-108.

Wang, C. L., Li, D., Barnes, B. R., \& Ahn, J. (2012). Country image, product image and consumer purchase intention: Evidence from an emerging economy. International Business Review, 21(6), 1041-1051.

Weber, Y., Yedidia Tarba, S., \& Reichel, A. (2009). International mergers and acquisitions performance revisitedthe role of cultural distance and post. In Advances in mergers and acquisitions (pp. 1-17).

Williamson P., Ramamurti R., Fleury A., \& Leme Fleury, M. T. (2013). The Competitive Advantage of Emerging Market Multinationals. Cambridge, MA: Cambridge University Press

Yamin, M., \& Forsgren, M. (2006). Hymer's analysis of the multinational organization: Power retention and the demise of the federative MNE. International Business Review, 15(2), 166-179.

YI, J. and YE, S. (2003). The Haier Way: The Making of a Chinese Business Leader and a Global Brand, Dumont, NJ: Homa \& Sekey Books.

Yildiz, H. E. (2014). Not all differences are the same: Dual roles of status and cultural distance in sociocultural integration in cross-border M\&As. Journal of International Management, 20(1), 25-37.

Yin, R.K. (2008). Applications of case study research (Applied Social Research Methods Series Volume 34). Sage: Newbury Park.

Zhang, J., Zhou, C., \& Ebbers, H. (2011). Completion of Chinese overseas acquisitions: Institutional perspectives and evidence. International Business Review, 20(2): 226-238. 